\title{
Temporal factors in visual perception as related to aging ${ }^{1}$
}

\author{
CHARLES W. ERIKSEN, ${ }^{2}$ UNIVERSITY OF ILLINOIS \\ AND ROY M. HAMLIN AND RUDOLF G. BREITMEYER, V.A. HOSPITAL, DANVILLE, ILLINOIS
}

Older Ss, in the age range 30-55 years, were compared on certain temporal characteristics of visual perception. Experiment 1 confirmed a previous finding that older adults required an appreciably longer exposure duration to identify forms, even when equated with younger adults on standard measures of visual acuity. Experiment 2 found that older adults have a longer critical duration over which time-intensity reciprocity holds for form identification. The results were discussed in terms of such concepts of psychological time as the psychological moment.

An ancillary result in a previously reported experiment (Eriksen \& Steffy, 1964) was a marked relationship between visual duration threshold for form identification and chronological age. While 60-year-old Ss were capable of achieving the same identification accuracy as 25-year-old Ss, they required 300- to $500-\mathrm{msec}$ exposure durations to do so, as compared with 10 to $30 \mathrm{msec}$ for the younger Ss. These duration differences could not be attributed to differences in acuity as normally measured since Ss at the various age levels were equated in terms of performance on the Snellen chart. It is known that sensory thresholds in general increase in aging $S s$ and that visual thresholds for light have shown rather pronounced effects of chronological aging (Hinchcliffe, 1962). Thus, it is possible that the increased exposure durations required by aged Ss may reflect their higher thresholds for light, but, if so, this would indicate a much longer critical duration over which time-intensity reciprocity holds than has been typically reported.

Although Kahneman (1966) has reported critical durations for time-intensity reciprocity of as long as $300 \mathrm{msec}$ on a form identification task, the more typical critical durations are in the neighborhood of $100 \mathrm{msec}$. In order for the older Ss to achieve the same performance level as the 25-year-olds with a suitable increase in exposure duration, they must integrate the light energy over more extensive periods than the typical critical duration.

An intriguing possibility is that the increase in form duration thresholds with advanced aging reflects a general slowing down of information-processing mechanisms. There has been a renewal of interest in such concepts as the psychological moment or the period of internal scanning processes (Kristofferson, 1965). These concepts might be relevant here, and one of the central characteristics of psychological aging may be the increased span of the psychological moment or a slower sweep or scan time.

Since the relation between chronological aging and exposure duration was an ancillary finding to the main purpose of the Eriksen and Steffy (1964) experiment, the first experiment reported below was carried out to verify the relationship before undertaking research designed to help to delineate more exactly the underlying basis for the effect.

\section{Method \\ EXPERIMENT 1 \\ Subjects. All Ss were male patients at} the Danville Veterans Administration Hospital. There were six in each of the age groups: 30 to 35 years, 40 to 45 years, and 50 to 55 years. They were selected on the basis of the following criteria: $20 / 25$ Snellen acuity or better in the dominant eye; no drug medication within the prior 6 weeks of the experiment; freedom from any indication of organic brain pathology; and a high degree of alertness and cooperativeness. In addition, all Ss were screened at the ophthalmology service at the hospital to insure freedom of ophthalmological diseases. Three Ss in each of the age groups achieved the acuity criterion without corrective lenses.

Since motivational variables could be a factor in differential performance with age, particular care was taken to insure maximum effort and cooperation from the Ss. All were volunteers, but in addition they were paid for their service in the form of canteen coupon books. Coffee and soft drinks were made available to them in the waiting room outside the experimental room.

Apparatus and stimuli. The acuity stimulus was a Landolt $C$, with a critical detail of $2.5 \mathrm{~min}$ of visual angle. It was presented as a photographic negative. The illuminated area of the $C$ had a luminance of $1.3 \mathrm{~mL}$ and a contrast with the ground in excess of $95 \%$. Two channels of a three-channel tachistoscope were used for stimulus presentation. One channel presented a faintly glowing $X$ fixation point, and the second channel was used to present the Landolt $C$ in one of four possible orientations: gap up, right, left, or down. The tachistoscope was timed by a Scientific Prototype Model GB tachistoscopic timer and lamp driver. Light sources were Sylvania F4T5/CWX fluorescent bulbs.

Procedure. To avoid excessive fatigue, all experimental sessions were approximately $1 / 2 \mathrm{~h}$ in length. The first two sessions were for practice and for further screening of Ss in terms of motivation and cooperativeness. In the third and last session, each $S$ made 20 judgments at each of five exposure durations: $10,25,50$, 100 , and $200 \mathrm{msec}$. At each exposure duration, the critical detail of the Landolt $C$ occurred equally often in each of the four quadrants in a random order, and after each trial $S$ was required to make a forced choice as to which of the four positions contained the gap.

Prior to beginning experimental sessions, Ss were dark adapted for a period of $10 \mathrm{~min}$. The adapting field of the tachistoscope had a luminance of less than $.1 \mathrm{~mL}$ and contained a faintly glowing $X$ fixation point that was located approximately $1 / 2 \mathrm{deg}$ of angle above the position where the Landolt $C$ was presented. All viewing was monocular with a 4-mm artificial pupil.

\section{Results and Discussion}

Results were evaluated in a modified two-way analysis of variance (age groups and exposure durations). The effects of exposure duration and age were both significant beyond the .01 level, but the interaction did not approach significance. The results are shown in Fig. 1, where per cent correct responses are shown as a function of exposure duration for each of the three age groups.

All three age groups show a similar and rapid improvement in performance with increasing exposure duration. The largest difference between groups occurs between the 30- to 35-year-olds and the 40. to 45-year-olds. However, comparison of the individual age group means shows that all three means differ from each other beyond the .05 level. On the average, Ss in the 40 to 45-year age range require 200-msec exposure duration to equal the performance achieved by the 30 - to 35-year-old Ss at an exposure duration of 
Fig. 1. Per cent correct detections of the critical detail as a function of age group and exposure duration.

$50 \mathrm{msec}$. Subjects in the 50- to 55-year age group have not achieved this performance level at a 200-msec exposure duration.

These results provide quite clear confirmation of the previous Eriksen and Steffy (1964) finding. The experiment, however, does not, nor was it intended to, deliniate the locus of these age differences. As noted above, the performance may reflect higher light thresholds for aged Ss. Thus, they would require greater energy to achieve the same acuity. The fact that all three age groups show appreciable gains in performance between the exposure duration of $100 \mathrm{msec}$ and that of 200 indicates that all groups are still integrating energy (if not completely) over an interval in excess of $100 \mathrm{msec}$.

Failure to find a significant interaction between age groups and exposure duration suggests that, for all three age levels, the integration of energy over time follows essentially the same function. This latter conclusion, however, needs to be tempered by the possibility that per cent correct forced-choice detections of the critical detail may not be linear with energy over its entire range. Thus, an improvement in performance from $85 \%$ to $90 \%$ correct may require more or less energy than an improvement in performance from $60 \%$ to $65 \%$ correct.

\section{EXPERIMENT 2}

The above experiment demonstrates quite clearly a relationship between aging and the exposure duration necessary to resolve the critical detail in a Landolt $\mathrm{C}$. It does not, however, for reasons enumerated above, provide information as to whether or not the length of the critical duration over which time-intensity reciprocity holds changes with advancing age. In Experiment 2, we have assessed the critical duration for form perception in Ss in the age range 30 to 55 years.

\section{Method}

Subjects. The Ss were the same as those employed in Experiment 1. All were run within a period of 1 month of their completing the previous experiment.

Procedure. The apparatus was the same as: that employed in the previous experiment. Landolt Cs were again employed as the target and were constructed in the same manner. Here, however, a series of Landolt Cs, varying in size and critical detail, was employed.

Fig. 2. Time-intensity functions for the three age groups.

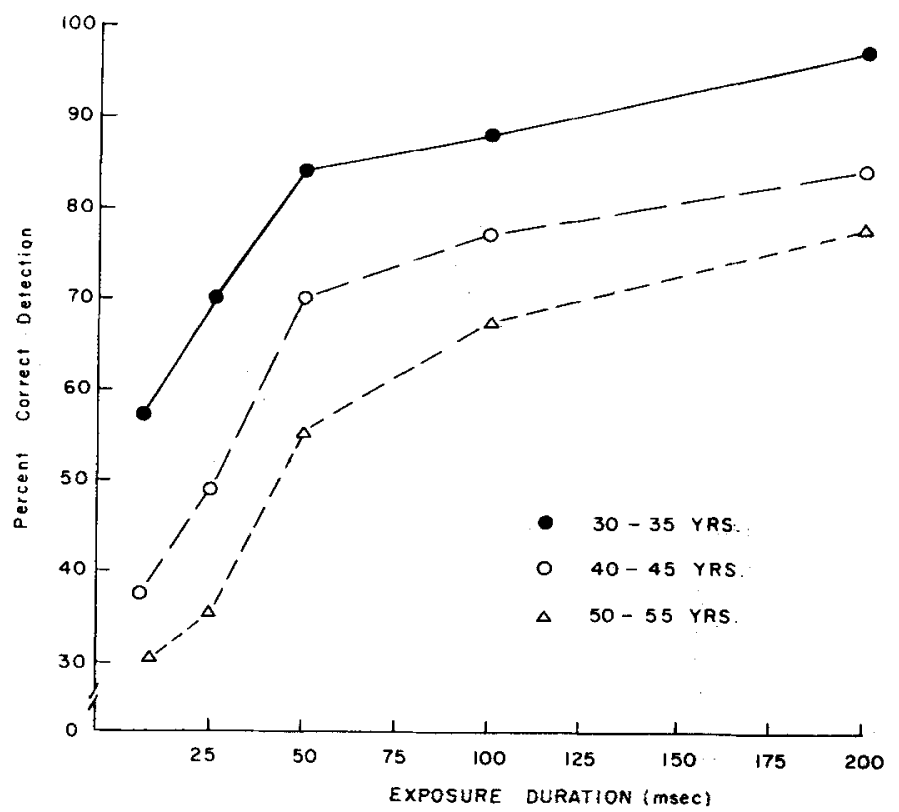

Before undertaking the experimental sessions, each $S$ participated in one or two practice sessions that were devoted to determining a size of a Landolt $\mathrm{C}$ that would yield approximately $75 \%$ correct four-interval forced-choice detections at an exposure duration of $10 \mathrm{msec}$ and a luminance of $1.3 \mathrm{~mL}$. This criterion was achieved with an average critical detail of $2.13 \mathrm{~min}$ of angle for the 30- to 35-year age group. The corresponding acuities for the 40 - to 45 -year-olds were $3.47 \mathrm{~min}$ of angle and 4.27 for the 50 - to 55 -year-olds. By this adjustment in the acuity requirement, all $\mathrm{Ss}$ were comparable in performance at the base level of $10 \mathrm{msec}$ of exposure at $1.3 \mathrm{~mL}$.

During the experimental sessions, time-intensity reciprocity was investigated over the duration range of 10 to $926 \mathrm{msec}$. The total energy of the stimulus integrated over time was kept constant

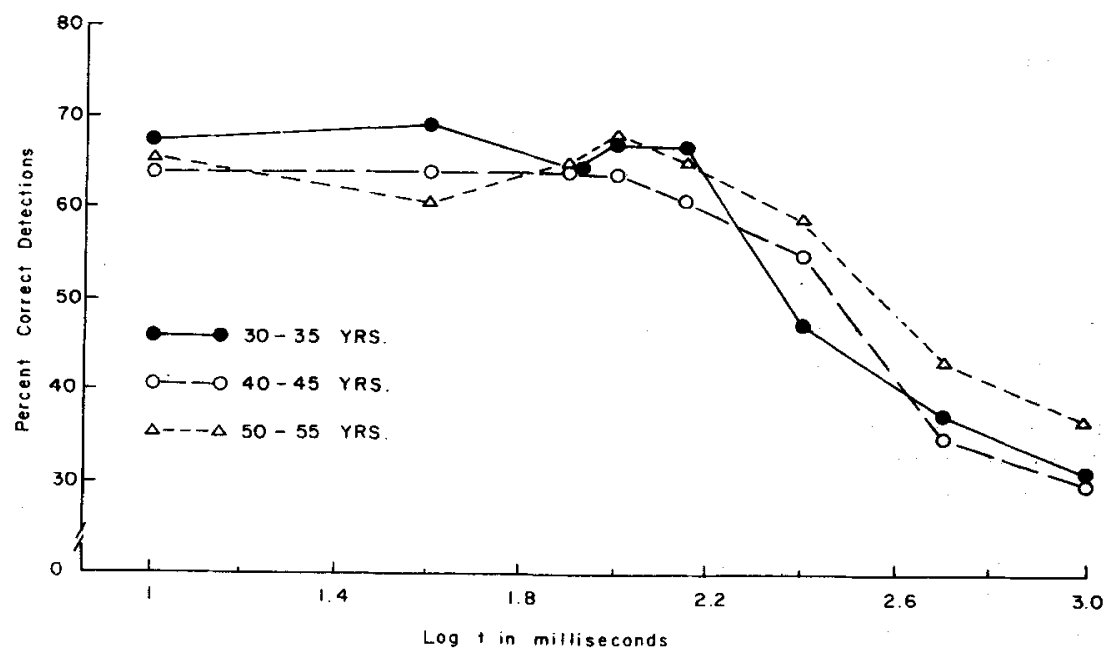

( $\mathrm{msec} \times \mathrm{mL}=13$ ) by reducing the luminance as time increased by means of neutral-density filters.

There was a total of four experimental sessions. In each session, $\mathrm{S}$ made a block of judgments at each of the exposure durations $(10,41,78,105,146,252,521$, and $926 \mathrm{msec}$ ). In each block of 12 judgments, the critical detail of the Landolt $C$ occurred in each of the four quadrants equally often. The order in which $S$ made judgments at each of the eight durations was counterbalanced within and across Ss. A total of 48 judgments was obtained for each $S$ at each of the eight exposure durations.

\section{Resuits}

Figure 2 shows the per cent correct detections of the location of the critical detail for each of the three age groups as a function of exposure duration (log $\mathrm{t}$ in 
milliseconds). The data were evaluated in a modified four-way analysis (age groups, exposure duration, quadrant containing critical detail, and Ss). Two main effects were significant, that due to exposure duration $[F(7,105)=82.2, p<.01]$ and that due to the quadrant in which the critical detail occurred $[F(3,45)=3.8$, $p<.05]$. The main effect of age group was not significant, a finding anticipated due to the equation of age-group performance under the base condition through manipulation of the size of the critical detail.

Of major interest was the interaction between age groups and exposure duration $[F(14,105)=1.9, p<.05]$. It was the only interaction approaching significance and reflects differential performance of the age groups as exposure duration is increased. From Fig. 2, it can be seen that, for all three age groups, time-intensity reciprocity begins to break down at an exposure duration between 146 and 252 msec. However, the break is a much sharper decline for $S_{3}$ in the 30 - to 35-year age bracket than it is for the older Ss. Performance for both the 40- to 45- and the 50- to 55-year-olds shows but little impairment as exposure duration is increased to $252 \mathrm{msec}$, but then both groups show a pronounced drop in performance with the 40 - to 45 -year-olds showing the sharper break.

The significant result for location of the critical detail was examined further. There was no significant or appreciable difference in detection accuracy when the critical detail was to the left, top, or right, but performance was significantly poorer if the gap was at the bottom.

\section{DISCUSSION}

The above results strongly suggest that the critical duration or time unit over which light energy is integrated does increase with advancing age. This lengthened integration period would account for the ability of the aged Ss, when given longer exposure durations, to achieve the acuity performance of younger Ss. The older Ss can compensate on this task for their heightened sensory threshold for light by integrating energy over a longer time period, thus effectively increasing the intensity of the stimulus. While the increase in the sensory threshold with advancing age may reflect impairment in the sense organ, the change in the integration period would definitely point to a more central locus for age changes.
Kahneman, Norman, and Kubovy (1967) have noted that while time-intensity reciprocity for brightness is probably mediated at the retina, the reciprocity obtained in form perception indicates central factors.

The increased critical duration in the elderly is compatible with the hypothesis that the psychological time unit, or moment, increases in terms of physical time with advanced age. The idea or concept of a psychological moment, or of a period of a central scanning process, has had a revival in recent years in psychology (Kristofferson, 1965; Stroud, 1956; White, 1963). One of the central facts around which the concept has been anchored has been the critical duration in vision. Completely satisfactory theoretical accounts of the integration period in vision have not as yet appeared, but, if Kristofferson's (1965) concept of a period of a central scanning process is employed, the critical duration or integration period might represent the time required for the central scanner to be directed to a given modality of stimulation. Integration in this modality or channel would occur over the period required before the scanner was able to read out the input. Thus, a slowing in the period of the scanning process would result in a longer period of integration.

The idea that physiological aging is characterized by an increased duration of the psychological moment is highly speculative. The viability of the moment concept has still to be demonstrated, but it does hold promise of accounting for many of the psychological characteristics of advancing years. The slowing of reaction time (Botwinick \& Brinley, 1962) and the slower shifts in attention that seem to characterize elderly drivers could be attributed to a psychological moment that has lengthened in physical time. Kristofferson (1965) has reported a negative correlation between his measures on the duration of the psychological moment in his Ss and the alpha frequency, and others (Murphree, 1954) have also reported correlation between alpha frequency and measures of a psychological time unit. These findings, coupled with a slowing of alpha frequency in aged Ss, are sufficient to encourage exploration in this research area.

A final comment is in order on the impaired detection of the critical detail when it occurred in the bottom quadrant. The result is consistent with other work using circular displays that have found impaired identification for form and for stimuli occurring in what corresponds to the 6 o'clock position with central fixation (Keeley, in press; Eriksen \& Rohrbaugh, in press). While this finding may reflect characteristics of some interval scanning process, in the present experiment the result is most likely attributable to the fact that the critical detail, when it occurred in the bottom position, was on a less sensitive foveal region. The Landolt $C$ was presented .4 of a degree below the fixation point. Thus, when the gap occurred in the bottom of the $C$, it was on a less sensitive foveal area than was the case for the other three quadrants.

\section{REFERENCES}

BOTWINICK, J., \& BRINLEY, J. G. Aspects of reaction time set during brief intervals in relation to age and sex. Journal of Gerontology, 1962, 17, 295-301.

ERIKSEN, C. W., \& ROHRBAUGH, J. Visual masking in multielement displays. Joumal of Experimental Psychology, in press.

ERIKSEN, C. W., \& STEFFY, R. A. Short-term memory and retroactive interference in visual perception. Journal of Experimental Psychology, 1964, 68, 423-434.

HINCHCLIFFE, R. Aging and sensory thresholds. Journal of Gerontology, 1962, 17, 45-50.

KAHNEMAN, D. Time-intensity reciprocity in acuity as a function of luminance and figure-ground contrast. Vision Research, 1966, 6, 207-216.

KAHNEMAN, D., NORMAN, J., \& KUBOVY, M. The critical duration for the resolution of form: Centrally or peripherally determined? Journal of Experimental Psychology, 1967, 73, 323-327.

KEELEY, S. M. Visual detection as a function of attentional demand and perceptual system error. Journal of Experimental Psychology, in press.

KRISTOFFERSON, A. B. Attention in time discrimination and reaction time. Unpublished Technical Report NASA CR-194, Bolt Beranek \& Newman, Cambridge, Massachusetts, 1965.

MURPHREE, O. D. Maximum rates of form perception and the alpha rhythm: An investigation and test of current nerve net theory. Joumal of Experimental Psychology, $1954,48,57-61$.

STROUD, J. M. The fine structure of psychological time. In H. Quastler (Ed.), Information theory in psychology. Glencoe, III: Free Press, 1956.

WHITE, C. T. Temporal numerosity and the psychological unit of duration. Psychological Monographs, 1963, 77(12, Whole No. 575).

\section{NOTES}

1. This investigation was supported by Public Health Service Research Grant MH-13434.

2. Address: Department of Psychology, University of Illinois, Urbana, Illinois 61801.

(Accepted for publication September 9, 1969.) 